\title{
Relationship between Crustal Temperature and Depth of Seismogenic Layer Estimated from the Inland Earthquakes along the Sea of Japan Beneath Japanese Islands
}

Tomoko Elizabeth Yano ( $\square$ tomoyano@gmail.com )

NIED https://orcid.org/0000-0001-9844-9110

\section{Makoto Matsubara}

National Research Institute for Earth Sciences and Disaster Resilience

Takumi Matsumoto

National Research Institute for Earth Science and Disaster Resilience

Tatsuya Ishiyama

Earthquake Research Institute, The University of Tokyo

\section{Full paper}

Keywords: Earthquake, Seismogenic zone, Crustal temperature, Earthquake Hazard, Crustal structure, 2003 northern Miyagi earthquake, 2004 Chuetsu earthquake, 2008 Iwate-Miyagi earthquake, 2016 Kumamoto earthquake, 2016 Tottori earthquake

Posted Date: February 9th, 2022

DOI: https://doi.org/10.21203/rs.3.rs-1313798/v1

License: (c) (i) This work is licensed under a Creative Commons Attribution 4.0 International License. Read Full License 


\section{Abstract}

We found the depth of the seismogenic layer based on D95, the cut-off depth at which $95 \%$ of the earthquakes occurred, from the event catalog before the mainshock of five major earthquakes, such as the 2003 Northern Miyagi, the 2004 Chuetsu, the 2008 Iwate-Miyagi, the 2016 Kumamoto, and the 2016 central Tottori earthquakes. Our results show that the main event depth, aftershock distribution, and main slip area are confined above the base of the seismogenic zone. A simple modelling of the geothermal gradient based on surface heat flow shows that the temperature at the base of the seismogenic zone is constrained to a range of $250-450{ }^{\circ} \mathrm{C}$. We confirmed that mainshock depths for five cases nucleated at the deepest portion of the seismogenic layer, and large rupture areas occurred within the seismogenic layer. Some aftershock streaks of the 2016 Kumamoto earthquake occurred at $5 \mathrm{~km}$ deeper than the bottom of seismogenic depth.

\section{Introduction}

Seismogenic depth is an important parameter influencing earthquake hazards and crustal mechanical properties. The cut-off depth distribution of seismicity has been interpreted as the brittle-ductile boundary of rock deformation (Kobayashi 1976; Chapman 1986; Ito 1993). Sibson (1982) examined the distribution of heat flow and cut-off depth of seismicity (D90) above which $90 \%$ of the shallow earthquakes occur in various continental settings in the United States and found a correlation between the theoretical frictional to quasi-plastic transition models and the observed cut-off depth. Scholz (1988) proposed a schematic diagram relating the temperature and depth to geologic features, fault rock mechanisms, friction rate behavior, seismic behavior, and strength of the structure for the major geological and seismological features, intended for quartzo-feldspathic rocks. The shallow part is a brittle zone as a seismogenic layer corresponding to temperatures of approximately $300^{\circ} \mathrm{C}$. Between 300 and $450^{\circ} \mathrm{C}$, it enters a brittleductile state and may partially rupture in the transition zone. In Japanese Islands, Tanaka and Ishikawa (2002) found a correlation between heat flow data and D90 beneath northeastern Japan. Their results follow the thermal structure derived from seismic tomography (Hasegawa et al. 2000). Tanaka $(2004,2009)$ showed the relationship between the temperature and depth of earthquake nucleation using actual seismic activity and temperature observations. This study indicates that the temperature of $250^{\circ} \mathrm{C}$ to $450^{\circ} \mathrm{C}$ corresponds to the $\mathrm{D} 90$, assuming a typical heat flow value of silicates.

The relationship between the size of earthquakes and thickness of the seismogenic layer has long been discussed. For example, Das and Scholz (1983) reported that large earthquakes tend to nucleate at the base of the seismogenic zone and often rupture the entire brittle seismogenic layer. Ito $(1990,1993)$ studied thickness of the seismogenic layer beneath the Japanese Islands and recognized its local depth variations. He suggested that the cut-off depth of seismicity is closely related to the depth of large crustal earthquakes with magnitudes greater than 7 where the seismic-aseismic boundary sharply changes. Hashimoto and Matsu'ura (2000) and Shibazaki (2002) argued that nucleation of the large earthquakes is determined by the seismic-aseismic boundary, where high gradients in strength and critical weakening displacement on the edges of the base of the seismogenic zone.

Studies have recognized the spatial distribution of the thickness of seismogenic layer beneath Japanese Islands. In a recent study, Omuralieva et al. (2012) estimated the spatial distribution of the D90 over the whole of Japan using relocated hypocenters, which eliminated interplate or intraslab events from the geometry of the subducting Pacific and Philippine Sea plates. They found that D90 is shallow in volcanic areas, the Kinki district, and the middle of Shikoku district and deep along the coastal area of the Pacific Ocean, with the lateral variation ranging from $5 \mathrm{~km}$ to $40 \mathrm{~km}$. 
In this research, we investigated the local variation of D95, the depth above which $95 \%$ of the earthquakes occurred, where major inland earthquakes stroked after 2001, such as the 2003 Northern Miyagi, the 2004 Chuetsu, the 2008 Iwate-Miyagi, the 2016 Kumamoto, and the 2016 central Tottori earthquakes. The hypocenter catalog to compute D95 was used as the seismic activity before the mainshock occurred. These events were relocated from the Hi-net earthquake catalog. We then compared the nucleation depth, aftershock area, estimated depths of 250,300 , and $450^{\circ} \mathrm{C}$, and seismic velocity structure corresponding to the D95.

\section{Materials And Methods}

We first calculated D95 for each event region from high-resolution catalog including hypocenters occurred before each mainshock. To justify the meaning of the value of D95, we needed to compare D95 to the depth range of hypocenter of mainshock, aftershocks, rupture area, and crustal temperature for each event region to find whether there is an agreement to D95. Additionally, we estimated the depth of the crustal temperature where it reaches $250{ }^{\circ} \mathrm{C}$, $300{ }^{\circ} \mathrm{C}$, and $450{ }^{\circ} \mathrm{C}$, hereinafter referred to as D250deg, D300deg, D450deg, respectively. In this section, we explain the method to prepare the dataset to calculate D95, D250-450deg and that to compare other seismic parameters.

\subsection{Earthquake event catalog}

The high-sensitivity seismograph network (Hi-net) operated by the National Research Institute for Earth Science and Disaster Resilience (NIED) has been under operation since 2000 and has been generating its own earthquake catalog using seismic records from Japanese multiple institutes and universities (Okada et al., 2004). Because seismometers of Hi-net are installed at the bottom of a borehole at depths of over $100 \mathrm{~m}$ at approximately 800 locations nationwide (with 20-25 km mesh) on Japanese Islands, their records contain relatively low noise with dense coverage. These seismic data are open to the public through the NIED MOWLAS website and are heavily used for earthquake research and for monitoring from micro- to mega earthquakes (Obara et al., 2005; National Research Institute for Earth Science and Disaster Resilience, 2019).

Yano et al. (2017) took advantage of this Hi-net seismic data to generate a high-resolution catalog called the "Japan Unified hIgh resolution relocated Catalog for Earthquakes" (JUICE), which is resolved highly enough to be used to evaluate the geometry of the local faults and seismogenic depth around active faults in Japan. In this study, we adopted the local relocated hypocenter catalog based on the JUICE catalog and its relocation method to prepare the dataset for computing D95.

Because Hi-net event catalog has been available from October 2000, we selected earthquakes with sufficient evidences such as, the number of available phase arrival time data. For three cases that occurred before 2012, the 2003 Northern Miyagi, the 2004 Chuetsu, and the 2008 Iwate-Miyagi earthquakes, we used the JUICE catalog to compute D95. This is because their full range of periods are covered by the JUICE catalog.

For the other two cases that occurred after 2012, the 2016 central Tottori earthquake, and the 2016 Kumamoto earthquake (based on Yano and Matsubara, 2017), we carried out relocation of earthquake events in the Hi-net catalog using the same method as JUICE to generate its own local relocated earthquake catalog; the hypocenter determination method called hypoDD (Waldhauser and Ellsworth, 2000) was adopted to refine the relative event locations by reducing the differential travel-time residual between pairs of events recorded at a common station. We applied the differential travel time data, including the waveform correlation data, and ordinal phase arrival time data to hypoDD algorithm under the weighting/reweighing parameters given in Table 1. Under these parameters, local high- 
resolution event catalogs were created for all five cases (detailed descriptions are in Table 2). These catalogs were based on the D95 calculation.

Table 1

Parameters for weighting scheme used for JUICE catalog and local event catalogs

\begin{tabular}{|c|c|c|c|c|c|c|c|c|c|}
\hline \multirow[t]{2}{*}{ Set } & \multirow[t]{2}{*}{ Iterations } & \multicolumn{4}{|c|}{ Cross correlation data } & \multicolumn{4}{|c|}{ Catalog data } \\
\hline & & $\begin{array}{l}\text { A priori, } \\
\text { P-wave } \\
\text { WTCCP }\end{array}$ & $\begin{array}{l}\text { A priori, } \\
\text { S-wave } \\
\text { WTCCS }\end{array}$ & $\begin{array}{l}\text { Misfit } \\
\text { weight } \\
\text { (residual } \\
\text { cutoff. } \\
\text { Factor } \\
\text { times } \\
\text { SD) } \\
\text { WRCC }\end{array}$ & $\begin{array}{l}\text { Dist. } \\
\text { Weight } \\
\text { (separation } \\
\text { in km) } \\
\text { WDCC }\end{array}$ & $\begin{array}{l}\text { A priori, } \\
\text { P-wave } \\
\text { WTCTP }\end{array}$ & $\begin{array}{l}\text { A priori, } \\
\text { S-wave } \\
\text { WTCTS }\end{array}$ & $\begin{array}{l}\text { Misfit } \\
\text { weight } \\
\text { (residual } \\
\text { cutoff. } \\
\text { Factor } \\
\text { times } \\
\text { SD) } \\
\text { WRCT }\end{array}$ & $\begin{array}{l}\text { Dist. Weigh } \\
\text { (separation } \\
\text { in km) } \\
\text { WDCT }\end{array}$ \\
\hline 1 & $1-6$ & 0.01 & 0.01 & -9 & -9 & 1.00 & 0.3 & -9 & -9 \\
\hline 2 & $7-12$ & 0.01 & 0.01 & -9 & -9 & 1.00 & 0.5 & 10 & 10 \\
\hline 3 & $13-18$ & 1.0 & 0.5 & -9 & 2 & 0.01 & 0.005 & 8 & 5 \\
\hline 4 & $19-24$ & 1.0 & 0.5 & 6 & 2 & 0.01 & 0.005 & 6 & 4 \\
\hline 5 & $25-30$ & 1.0 & 0.5 & 6 & 0.5 & 0.01 & 0.005 & 6 & 4 \\
\hline
\end{tabular}

Table 2 Relocation parameters for relocated hypocenter used for D95 and aftershock catalog

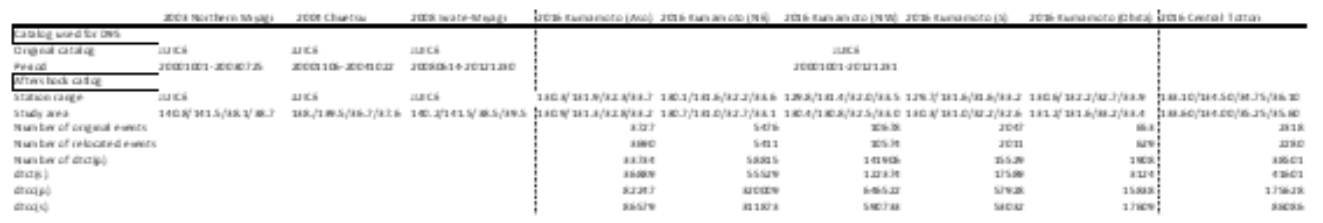


In this study, D95 was used to estimate the depth corresponding to the seismogenic depth. The seismogenic depth has been thought as the depth of onset of quartz plasticity as well as temperature above $300^{\circ} \mathrm{C}$ (Scholz 1998), assuming the presence of quartz as a dominant mineral in the crust. Earthquakes were selected from magnitudes larger than M1.5 from the relocated catalog (see section 2.1). This selection satisfies the Gutenberg-Richter rule for proper analysis. Only the crustal events, shallower than the depth of $40 \mathrm{~km}$, between 2001 and the time before the mainshock were considered to compute D95. This is because we wanted to verify if any pre-condition can predict the maximum depth of the main event before the mainshock occurred. The final D95 result is available at every grid point, evenly spaced at $0.1^{\circ}$ in the latitude and longitude directions. To calculate D95, we first counted the total number of earthquakes that occurred within the depth column. The dimension of this depth column is $0.02^{\circ} \times 0.02^{\circ}$ (latitude $\times$ longitude) $\times$ depth. Then, we resampled by averaging the final grid points evenly spaced at $0.1^{\circ}$. The size of grid space is justified by the fact that it is larger than the location uncertainty of the JUICE catalog, $0.37 \mathrm{~km}$ and $0.85 \mathrm{~km}$ in the horizontal and vertical direction, respectively, in the good station coverage. We assumed these uncertainties are compatible with this study because we used similar station combinations and the same technique as the JUICE catalog. D95 was left as an undetermined value if the total number of events within the depth column is less than 50 events due to the insufficient sample size.

\subsection{D250deg - D450deg}

We used the combined borehole temperature measurements of Matsumoto (2007) and Sakagawa et al. $(2004,2005)$. The data by Matsumoto (2007) contains a total of 663 temperature measurements at Hi-net borehole sites. The temperature profile ranges from the surface to about $300 \mathrm{~m}$ in depth. Those by Sakagawa et al. $(2004,2005)$ contain a total of 1099 measurement sites. Their temperature measurements were taken from the surface to approximately $1000 \mathrm{~m}$. Using these measurements, we estimated the temperature profile in depth for our study regions. For estimating the heat flow at sites measured by Sakagawa et al. $(2004,2005)$, we used the difference of top and bottom temperature and thermal conductivity. If thermal conductivity is not listed, we adopted $2.5 \mathrm{~W} \mathrm{~m}-1 \mathrm{~K}-1$ (Fowler 2005). Then, these heat flow data were used to estimate the isotherms at 250,300 , and $450^{\circ} \mathrm{C}$ (hereafter referred as D250deg, D300deg, and D450deg, respectively) using the steady-state one dimensional heat conduction equation with an exponential decrease in the radioactivity heat generation (e.g., Lachenbruch, 1970), as follows:

[Equation 1] (Turcotte and Schubert 1982).

We estimated the isotherm using the following parameters introduced by Tanaka(2009). $\mathrm{T}_{0}$ as $13.51^{\circ} \mathrm{C}$ is the average temperature of the ground surface all over Japan (National Astronomical Observatory 1998); $q_{0}$ is the surface heat flow obtained from the temperature data; $A$ as $1.4 \mu \mathrm{Wm}^{-3}$, is the average heat production of the continental crust, $\mathrm{k}$ is the average thermal conductivity from the data, otherwise $2.5 \mathrm{~W} \mathrm{~m}^{-1} \mathrm{~K}^{-1}$ (Fowler 2005); $\mathrm{Z}_{1}$ as $10 \mathrm{~km}$ is the characteristic thickness of the layer enriched in radioactive elements has been estimated (Turcotte and Schubert, 1982); $Z$ is the depth where temperature becomes $T$. Therefore, we solved for $Z$ for each $T$ (i.e., $250,300,450^{\circ} \mathrm{C}$ ). Alternatively, Tanaka (2009) varies two parameters A as $1.8 \mu \mathrm{Wm}^{-3}$ (Fowler 2005) and k as $3 \mathrm{~W} \mathrm{~m}^{-1} \mathrm{~K}^{-1}$ (median value from Stein (1995)). The result by Tanaka (2009) shows that estimated temperature changes by approximately $50{ }^{\circ} \mathrm{C}$ due to the uncertainty in the thermal properties of the shallow and deep rocks alone. This result implies that D300deg can change up to about $4 \mathrm{~km}$ due to uncertainty in the thermal properties. Another caveat is that it is possible for very hot fluids reaching the surface, crustal structure, climate change, and heat sources can alter the geothermal profile. Further discussion of this caveat is in the discussion session. 


\subsection{Vertical cross-sections along the coseismic faults of large earthquakes}

We obtained the vertical cross-sections along the approximate fault locations which intersect with main aftershocks and mainshocks for the 2003 Northern Miyagi, the 2004 Chuetsu, the 2008 Iwate-Miyagi, the 2016 Kumamoto, and the 2016 central Tottori earthquakes. We then compared (1) the D95 depth with 5 other parameters; (2) patterns of D250-450deg, (3) hypocenters of mainshocks and (4) their aftershocks, (5) their coseismic rupture from results by Honda et al. (2005) for the 2004 Chuetsu earthquake, Suzuki et al. (2010) for the 2008 Iwate-Miyagi earthquake, Kubo et al. (2016) for the 2016 Kumamoto earthquake, and Kubo et al. (2017) for the 2016 central Tottori earthquake, and (6) local velocity structure from Matsubara et al., 2019. In figures 1-5, D300deg are interpolated from the D300deg result; We used the GMT command "surface" with $0.5^{\circ}$ as the search radius and eight maximum iterations to obtain the minimum curvature solutions for the $0.05^{\circ}$ grid. D95 in the map view is not interpolated but shown in color corded circle. The color indicates the D95 at the site. Note that the cross-sections are all vertical cut. This means that if a coseismic fault has low-angle dipping, the interpretation from the cross-section figure is needed to be cautious. For our reference, we inserted the F-net CMT solutions.

\section{Results}

The summary of results is shown in Table 3. D95 and D250-D450degs do not remain constant locally for most cases, rather fluctuate about $4 \mathrm{~km}$ and $19 \mathrm{~km}$ in depth at most, respectively. Except for some aftershocks that occurred in the southwestern part of the Kumamoto earthquake penetrated $5 \mathrm{~km}$ deeper than D95, mainshock hypocenters and their aftershocks nucleated mainly above the D95 and D250-450degs. Therefore, our results indicate that D95 is suitable representation for the base of the seismogenic layer. Isodepth surface of D95 lies within Vp/Vs (the ratio of compressional wave velocity to shear wave velocity) of the range between 1.68 and 1.82 and $\mathrm{Vp}$ (compressional wave velocity) of the range between 5.9 and $6.8 \mathrm{~km}$. For most cases, mainshock occurred in the region between D300deg and D450deg. Except for mainshocks of the Iwate-Miyagi earthquake occurred about $2 \mathrm{~km}$ deeper than D450deg and of the Kumamoto earthquake occurred in the range between D250deg and D300deg. Overall patterns of D250-450deg and D95 are compatible particularly to Vp/Vs structure. However, the patterns of D250-450deg for the Iwate-Miyagi earthquake is extremely shallow and for the epicentral region of the Kumamoto earthquake is extremely deep. 
Table 3

Summary of results for all five study regions

\begin{tabular}{|c|c|c|c|c|c|c|c|}
\hline & 2003 & 200 & & 2008 & 201 & & 2016 \\
\hline & $\begin{array}{l}\text { Northern } \\
\text { Miyagi (Fig. 1) }\end{array}$ & $\begin{array}{l}\text { Chu } \\
\text { (Fig. }\end{array}$ & & $\begin{array}{l}\text { Iwate-Miyagi } \\
\text { (Fig. 3) }\end{array}$ & $\begin{array}{l}\text { Kum } \\
\text { (Fig. }\end{array}$ & 1oto & $\begin{array}{l}\text { central Tottori } \\
\text { (Fig. 5) }\end{array}$ \\
\hline 1. D95 (km) & $12-13$ & sw & NE & $8-18$ & $10-$ & & 13 \\
\hline & & 22 & 17 & & & & \\
\hline 1. D450deg & $11-18$ & 22 & 8 & $3-5$ & sW & NE & $7-16$ \\
\hline (km) & & & & & $\begin{array}{l}25- \\
30\end{array}$ & $\begin{array}{l}3- \\
6\end{array}$ & \\
\hline 3. & $12.3 / 13.6$ & 14.1 & 14.8 & 6.7 & $\begin{array}{l}12.6 \\
(4 / 1\end{array}$ & & $11.6 / 10.1$ \\
\hline $\begin{array}{l}\text { depth (Hi- net/our local } \\
\text { relocated catalog) [km] }\end{array}$ & & & & & $\begin{array}{l}13.1 \\
(4 / 1\end{array}$ & & \\
\hline
\end{tabular}

\begin{tabular}{|c|c|c|c|c|c|}
\hline $\begin{array}{l}4 . \\
\text { Aftershock }\end{array}$ & $5-15$ & $5-20$ & $3-13$ & $\begin{array}{l}\text { Most: 5-15 } \\
\text { SW:20 }\end{array}$ & $5-15$ \\
\hline 5. Main slip & unknown & $\begin{array}{l}3-20 \\
\text { (Honda } \\
\text { et al. } \\
\text { 2005) }\end{array}$ & $\begin{array}{l}2-6 \\
\text { (Suzuki } \\
\text { et al., 2010) }\end{array}$ & $\begin{array}{l}\text { 0-15 } \\
\text { (Kubo et al., } \\
2016)\end{array}$ & $\begin{array}{l}\text { 4-13 } \\
\text { (Kubo et al., 2016) }\end{array}$ \\
\hline $\begin{array}{l}\text { 6. Vp }(\mathrm{km} / \mathrm{s}) \\
\mathrm{Vp} / \mathrm{ks}\end{array}$ & $\begin{array}{l}6.2-6.4 \\
1.68- \\
1.76\end{array}$ & $\begin{array}{l}6.1-6.8 \\
1.76-1.82\end{array}$ & $\begin{array}{l}6.0-6.3,1.70- \\
1.78\end{array}$ & $\begin{array}{l}5.9-6.4 \\
1.68-1.74\end{array}$ & $\begin{array}{l}6.2-6.3 \\
1.72-1.74\end{array}$ \\
\hline
\end{tabular}

\subsection{Case 1. The 2003 Northern Miyagi earthquake}

D95 was undetermined due to a lack of sufficient background seismicity events before the mainshock listed in the Hinet catalog (Figure $1(\mathrm{a}, \mathrm{d})$ ). Instead, D95 of 12-13 km estimated in the northern extension of the study region was used for this study case. We confirmed that the mainshock occurred near D95 by comparing the depth of D95 as 12$13 \mathrm{~km}$ to the depth of mainshock nucleated is at $12.3 \mathrm{~km}$ according to Hi-net catalog; and $13.6 \mathrm{~km}$ in JUICE catalog (Yano et al., 2017).

D250-450deg are the range of 7 and $18 \mathrm{~km}$ (Figure $1(\mathrm{~b}, \mathrm{e})$ )). Isotherm along the cross-section is deep in the southern part and shallower by $5 \mathrm{~km}$ in the northern part. Aftershocks mainly occurred within the range of 5 to $15 \mathrm{~km}$. The mainshock and main aftershock were located within the D300-D450deg between 11-18 km, apparently within a depth of D250-450deg.

$\mathrm{Vp}$ along the cross-section in Figure $1(\mathrm{~g})$ is nearly layered structure as well as $\mathrm{Vp} / \mathrm{Vs}$ except there were two low $\mathrm{Vp} / \mathrm{Vs}$ zones in the epicentric region and its northern extension (Figure $1(\mathrm{~h})$ ). The distribution of seismicity is mainly above 
these two low Vp/Vs zone. D95, D250-450deg, and Vp gently lean southward to deeper. D95 laid within the narrow Vp range between 6.2 and $6.4 \mathrm{~km} / \mathrm{s}$ and within the $\mathrm{Vp} / \mathrm{Vs}$ range between 1.68 and 1.76.

\subsection{Case 2. The 2004 Chuetsu earthquake}

Overall D95 pattern in this region (Figure 2 (a)) tend to be deeper, compare to those in the other study areas. D95 varies from about $17 \mathrm{~km}$ to $22 \mathrm{~km}$ in depth and appears to deepen northward in the cross-section (Figure 2 (d)). Particularly, the deepest D95 is located at about $10 \mathrm{~km}$ southwest of the mainshock. Focal depth of the mainshock, as $14.1 \mathrm{~km}$ according to the Hi-net event catalog and $14.8 \mathrm{~km}$ in JUICE catalog (Yano et al., 2017) are shallower than the D95. Majority of aftershocks occurred between 5 and $15 \mathrm{~km}$ in depth, with the sprinkling deep events. Main coseismic slip was estimated around 3-20 km in depth (Honda et al., 2005). Therefore, D95 lies deeper than the hypocenter of the mainshock, majority of aftershocks, and area of large coseismic slips. D250deg is about 4-10 km in depth and D450deg is about 8-22 km (Figure 2 (b, e)). D250, 300, 450deg are shallow in the northeastern area and deep in the southwestern area. This pattern is similar to D95 curve. High Vp zone and Vp/Vs can be seen around $20 \mathrm{~km}$ in depth at southwest from the mainshock (Figure $2(\mathrm{~g}, \mathrm{~h})$ ). This high Vp zone and Vp/Vs location is compatible to the region where D95 and D250-450deg both be deeper. D95 laid within the Vp range of between 6.1 and $6.8 \mathrm{~km} / \mathrm{s}$ and within the $\mathrm{Vp} / \mathrm{Vs}$ range of between 1.76 and 1.82 .

\subsection{Case 3. The 2008 Iwate-Miyagi earthquake}

D95 is relatively within a narrow range between 9-11 km in depth near the mainshock hypocenter (Figure 3 (a, d)), whereas its northeastern part is extremely deep to $18 \mathrm{~km}$. Hypocenter of the mainshock lies at a depth of $6.7 \mathrm{~km}$. Aftershocks are located between 3 to $12 \mathrm{~km}$ in depth and can be subdivided into two segments based on their spatial patterns; in a southern segment, aftershock clouds exhibit concave up between 3 and $-12 \mathrm{~km}$, whereas they appears more flat in a northern segment between 9 and 4 km (Figure 3 (e)). D95 encloses most of these deeper portion aftershocks distributions. Main coseismic slip was estimated around 2-6 km in depth (Suzuki et al., 2010). Therefore, D95 lies below the hypocenter of the mainshock, and the deeper bound of where majority of aftershocks and coseismic rupture occurred. In contrast to other cases, D250-450deg is very shallow at a depth of 1-5 km (Figure 3 (b, e)). D250-450deg is much shallower than D95. There are low Vp/Vs zones around $10 \mathrm{~km}$ away in both strike directions from the mainshock (Figure $3(\mathrm{~h})$ ). High Vp/Vs zone penetrates about $3 \mathrm{~km}$ deeper just beneath the mainshock. This concave pattern of high $\mathrm{Vp} / \mathrm{Vs}$ is comparable to the pattern of aftershock distribution and D95. D95 lies within the $\mathrm{Vp}$ between 6.0 and $6.3 \mathrm{~km} / \mathrm{s}$ (Figure $3(\mathrm{~g})$ ) and within the $\mathrm{Vp} / \mathrm{Vs}$ between 1.7 and 1.78.

\subsection{Case 4. The 2016 Kumamoto earthquake}

Except epicentric area, shallower D95 and D300deg of about $10 \mathrm{~km}$ in depth lies along a wide range of the BeppuShimabara graben where our cross-section runs (Figure $4(\mathrm{a}, \mathrm{b})$ ). D95 tend to be slightly deeper about $3 \mathrm{~km}$ at southwest than northeast along the cross-section (Figure $4(\mathrm{a}, \mathrm{c})$ ). Cloud of background seismicity before the mainshock appear to be shallower around Mt. Aso area (Figure 4 (d)). Majority of aftershocks occurred down to 13 $\mathrm{km}$ and becomes shallow in the vicinity of Mt. Aso. This pattern is similar to D95. There are less aftershocks southwest of Mt. Aso region. Some streaks of aftershocks penetrated about $5 \mathrm{~km}$ deeper than D95. Mainshocks occurred on April 142016 and April 162016 had depths of 12.6 km (12.2 km in Yano and Matsubara, 2007) and 13.1 (12.7 km in Yano et al., 2007) km respectively. Main co-seismic slip was estimated around 0-15 km in depth (Kubo et al., 2016). Therefore, D95 lies below the hypocenter of the mainshock, and the bases of where majority of aftershocks occurred, and on the deeper limit of co-seismic rupture.

D250deg, D300deg, and 450deg vary in wide range about between $3 \mathrm{~km}$ and $14 \mathrm{~km}$, between $6 \mathrm{~km}$ and $18 \mathrm{~km}$, and between $8 \mathrm{~km}$ and $30 \mathrm{~km}$ in depth, respectively (Figure 4 (d)). Particularly, deepest depths of all D250-450deg are at 
about $10 \mathrm{~km}$ to the southwest from the mainshock along the cross-section. D450deg appears to enclose the deep streaks of aftershocks. There is a shallower kink in the pattern at the southwest from Mt. Aso region in the same area of less aftershock activity. Depths of mainshocks are on or slightly above the D300deg.

Layered structure of $\mathrm{Vp}$ and $\mathrm{Vp} / \mathrm{Vs}$ can be seen generally except Mt. Aso region (Fig. $4(\mathrm{e}, \mathrm{f})$ ). Low Vp layer stretching out the surface along the cross-section depresses about $10 \mathrm{~km}$ in depth around Mt. Aso region. Low Vp/Vs zone rises to shallower depth about $5 \mathrm{~km}$ than underneath Mt. Aso region. D95 lies within the Vp between 5.9 and $6.4 \mathrm{~km} / \mathrm{s}$ and within the $\mathrm{Vp} / \mathrm{Vs}$ between 1.68 and 1.74 .

\subsection{Case 5. The 2016 central Tottori earthquake}

D95 gives a constant value about $13 \mathrm{~km}$ in depth along the cross-section near the source region of the 2016 central Tottori earthquake (Figure $5(\mathrm{a}, \mathrm{c})$ ). Hypocenter of the mainshock was located at a depth of $11.6 \mathrm{~km}$ according to the Hi-net catalog (10.1 km in the local relocated catalog). Background seismicity before the mainshock was slightly active in the vicinity of mainshock hypocenter (Figure 5 (c)). Clouds of aftershocks can be seen mainly in the southeast of the cross-section at a depth of shallower than $15 \mathrm{~km}$ (Figure 5 (d)). Main coseismic slip was estimated around 4-13 km in depth (Kubo et al., 2016). Therefore, D95 lies below the hypocenter of the mainshock and coseismic rupture and on or near the deeper limit of the cloud of aftershock.

D250deg, D300deg, and 450deg run between 3 and $8 \mathrm{~km}$, between 4 and $10 \mathrm{~km}$, and between 7 and $16 \mathrm{~km}$ in depth, respectively (Figure $5(b, d)$ ). They commonly have a trend to become deeper toward the southeast along the crosssection. While aftershocks occurred much deeper than the D250-450deg in the northwest the mainshock nucleated between D300deg and D450deg. D95 lies within the Vp between 6.2 and $6.3 \mathrm{~km} / \mathrm{s}$ and within the Vp/Vs between 1.72 and 1.74 (Figure $5(e, f))$.

\section{Discussion}

\subsection{Case 1. The 2003 Northern Miyagi earthquake}

The 2003 Northern-Miyagi earthquake occurred at the eastern edge of the Miocene northern Honshu rift system (Sato et al., 2004a), and the damaged area is the boundary between the Neogene rocks and the Paleozoic and Mesozoic rocks of the Kitakami Mountains (Kato et al., 2004). Marine Miocene sedimentary rocks spread widely in the Asahiyama and Sue Hills. The Miocene basin fill is subdivided into two units; the Matsushima-wan Group composed of mainly syn-rift sediments such as volcanic rocks, fluviolucastrine sediments and marine-interbedded sandstone and siltstone in ascending order and the Shida Group composed of post-rift sediments such as a shallow marine sandstone (Ishii et al., 1982; Kato et al., 2004).

Hypocenters are located at downward extension of a west-dipping, inverted reverse fault (Sue fault) (Umino et al, 2003; Nishimura et al., 2003; Kato et al., 2004; Kimura and Okamura, 2009). Both the Sue fault was originally formed in the extensional stress field during the Miocene opening Sea of Japan and reactivated in the compression stress field due to the subduction of the Pacific plate during Quaternary (Sato et al., 2004b).

Background seismicity before the mainshock was relatively quiet so that D95 was undetermined due to a lack of sufficient data. However, there were at least three major historical earthquakes occurred in 1861, 1900, and 1962 in the north extension of the study region. We assumed that these historical earthquakes and the 2003 Northern Miyagi earthquake are related to each other, so that we borrowed D95 value from the north extension region. The mainshock depth and D95 turn out to be compatible in this case, however, D250-450deg in this seismically inactive area is going 
to be critical to understand the seismogenic depth. We re-estimated D250-450deg from latest method (Matsumoto et al., 2022), which included a careful analysis for climate change correction and crustal thermal structure based on the sedimentary layers, rather than a uniform subsurface structure model, the temperature dependence of thermal conductivity, and the difference in heat generation by lithology.

D300deg maps in both Figure 1 (b) and Figure 1 (c) show similar patterns with D95 (Figure 1 (a)) being shallower toward to the west. However, a new D300deg shows better fit with D95 than the original result, particularly more moderate change in depth towards the northwestern region. D250-450deg cross-sections in both Figure 1 (e) and (f) appear compatible with Vp/Vs and aftershocks patterns as relatively a flat and constant depth. However, because of new D250deg-450deg (Figure 1 (f)) and high Vp/Vs (around 1.8) being shallower in the south than the north, new result is better fit with the Vp/Vs pattern. Because the new D450deg (Figure 1 (f)), in the epicentral region, is shallower about $5 \mathrm{~km}$ than the original result (Figure 1 (e)), the location of the mainshock falls onto D450deg isotherm. The kinks in the D250-450deg isotherms at about $12 \mathrm{~km}$ to the north from the epicenter may be artifact since it is due to the one extreme value at the temperature measurement point.

\subsection{Case 2 The 2004 Chuetsu earthquake}

The 2004 Chuetsu earthquake occurred in the Niigata Basin that is filled by $>6 \mathrm{~km}$ thick sedimentary and volcaniclastic rocks (Niigata Prefectural Government, 2000). Structural analyses and stratigraphy of Neogene strata in this region suggest that reverse faults and fault-related folds have grown in the last 2 to 3 million years due to EW compression (Sato, 1992).

We re-estimated D250-450deg from latest method (Matsumoto et al., 2022), which included a careful analysis for climate change correction and crustal thermal structure based on the sedimentary layers, rather than a uniform subsurface structure model, the temperature dependence of thermal conductivity, and the difference in heat generation by lithology. D95 in Figure 2 (a) and D300deg maps for both Figure 2 (b) and Figure 2 (c) show similar patterns as being deeper toward Sea of Japan. Particularly, D95 reaches deeper than $30 \mathrm{~km}$ near the Sea of Japan.

D250-450deg in both Figure 2 (e) and (f) appears compatible with Vp/Vs and aftershocks patterns as deeper in the southwest. However, new D250deg-450deg in Figure 2 (f) shows better fit with D95 (Figure 2 (a)), particularly aftershocks and $\mathrm{Vp} / \mathrm{Vs}$ are having a concave upward pattern in the southwest from the mainshock.

\subsection{Case 3 The 2008 Iwate-Miyagi earthquake}

The 2008 Iwate-Miyagi earthquake struck with a magnitude of 7.2 near the volcanic front in the eastern flank of the Ou Backbone Ranges in Northern Japan. It recorded over $4 \mathrm{G}$ at the ground surface in the source region (Aoi et al., 2008). The epicenter was located to the northeast of Mt. Kurikoma, a Quaternary active volcano, and this event caused many landslides, debris flows and landslide dams. Similar to the 2003 Northern Miyagi earthquake which occurred in the south from the 2008 Iwate-Miyagi earthquake, this earthquake occurred near the eastern edge of the Miocene failed rift (Sato, 1994). In the source region of this earthquake, there are many west-dipping Miocene normal faults reactivated as reverse faults under the EW compressional stress field since Pliocene (Kato et al., 2006). The basement rocks of the source region are Cretaceous granitoids (Sasada, 1985).

We re-estimated D250-450deg from latest method (Matsumoto et al., 2022), which included a careful analysis for climate change correction and crustal thermal structure based on the sedimentary layers, rather than a uniform subsurface structure model, the temperature dependence of thermal conductivity, and the difference in heat generation by lithology. Isotherms of D250deg-450deg are much shallower than D95 (Figure 3). These extremely shallow isotherms may be affected by active volcanoes close to this region. 
D300deg maps in both Figure 3 (b) and Figure 3 (c) show similar patterns with D95 (Figure 3 (a)) being shallower at the epicentric region and the southwest from the epicenter. However, a new D300deg in Figure 3 (c) shows better fit with D95 than the original result (Figure 3 (b)), particularly concentrated shallow depth in the volcanic region. D250450deg cross-sections in both Figure 3 (e) and Figure 3 (f) appear compatible with the pattern of high Vp/Vs (around $1.8)$ as relatively a flat depth while they are not alike to the aftershock's patterns. Mainshock hypocenter is below the D450deg. Although new D250deg-450deg (Figure 3 (f) in the northeast give deeper depth which are slightly closer to the aftershocks in the area, new method for D250deg-450deg is not dramatically improve the original result. This result confirmed that an active volcanic region is challenging and need more consideration to estimate the seismogenic depth by heat flow data.

\subsection{Case 4 the 2016 Kumamoto earthquake}

The 2016 Kumamoto earthquake occurred at the Futagawa and Hinagu faults located at the topographic boundary between the Kumamoto and Yatsushiro plain and the foothills composed of Cretaceous accretionary complex and Jurassic metamorphic rocks. Aftershocks occurred along the Beppu-Shimabara graben and the southern side of the graben (National Institute of Advanced Industrial Science and Technology, 2016a).

While the most of the aftershocks occurred within the seismogenic layer, we found an exception in the aftershock distribution pattern during the 2016 Kumamoto earthquake below the southwestern strand of the Futagawa fault near the junction with the Hinagu fault (Figure 4); aftershocks apparently extend $5 \mathrm{~km}$ deeper than D95, which are significant considering that uncertainty of the hypocenter locations from the JUICE catalog is about $1 \mathrm{~km}$ in the depth direction. The estimated temperature of aftershock area is between $300^{\circ} \mathrm{C}$ and $450^{\circ} \mathrm{C}$. The isotherm in this region is significantly deeper than that in the other part of the Futagawa Fault. This deep isotherm is constrained by the temperature data from station \#1129 at Azumimachi, Uto (Sakagawa et al., 2005). The temperature profile taken from $100 \mathrm{~m}$ to $900 \mathrm{~m}$ for every $100 \mathrm{~m}$ in depth shows that subsurface temperature increases nearly linearly, indicating that the effect of local heat source on the data is apparently minimal. However, because the simple method we used in this analysis has limitation to estimate the crustal temperature in the complex system of extremely active groundwater flow region, extremely deep D250-450deg around a depth of $30 \mathrm{~km}$ may not be significant. The Vp and Vp/Vs values in the region where deep aftershocks occurred are approximately $6.5 \mathrm{~km} / \mathrm{s}$ and 1.7, respectively (Matsubara et al. 2019). These ranges are not extra ordinary to be in the seismogenic zone since they are within the range in the other cases. Immediate deepening from pre-earthquake level was also recognized by the 1992 M 7.3 Landers earthquake. The seismic-aseismic transition changes to shallower as much as $3 \mathrm{~km}$ over the course of 4 years (Rolandone et al., 2004). They claimed that the brittle-ductile transition became deeper after Landers due to high postseismic stress and strain rates at the base of the seismogenic zone. The time-dependent changes of depth relation of the postseismic seismicity of Kumamoto earthquake may be important to monitor to understanding the mechanical behavior of rocks in the crust.

\subsection{Case 5 the 2016 central Tottori earthquake}

The mainshock and aftershocks of the 2016 central Tottori earthquake occurred where pre-Neogene basement rocks mainly composed by late Cretaceous and Paleogene granitic rocks are extensively exposed. While there are some minor active faults which are striking NE-SW and NW-SE, orthogonal to NE-SW, recognized around the mainshock (RGAFJ, 1991) and no major fault is known at the mainshock and aftershock region (National Institute of Advanced Industrial Science and Technology, 2016b).

\subsection{Relationship between D95 and aftershock area, seismogenic layer, nucleation, and rupture process}

Page $11 / 23$ 
Both background seismicity before mainshocks and seismicity after the mainshock tend to be occurred at Vp/Vs in the green color region (1.7-1.8) in Figure 1-5. Therefore, the analysis of Vp/Vs pattern is also shed light on understanding the seismogenic depth and forecasting the future aftershock regions.

Our observation confirmed that large earthquakes nucleated at the base of the deepest portion of the seismogenic layer (e.g., Sibson 1984) The nucleation depths for the main shocks and the deepest portion of the main co-seismic rupture are near or shallower than D95 for all 5 cases. Therefore, our results support that D95 is indeed a significant index for the base depth of the seismogenic layer.

For the solid crust, climate change correction and the temperature dependence of thermal conductivity and the difference in heat generation by lithology should be precisely applied in the equation at each study site. These parameters in equation 1 can be arguable since a continental crust, especially complicated island arcs as Japanese Islands, may not be suitable to estimate the crustal temperature. We partially applied the latest temperature models (Matsumoto et al, 2022) to the 2003 northern Miyagi, the 2004 Chuetsu, and the 2008 Iwate Miyagi earthquakes (Figure 1 ( $c$ and f), Figure 2 (c and f), Figure 3 (c and f)). These models are obtained by a crustal structure model that considers the temperature dependence of thermal conductivity, the difference in heat generation due to lithology, and local climate differences. New version of isotherms tends to fit better with $\mathrm{Vp} / \mathrm{Vs}$ patterns and aftershock distributions.

\section{Conclusion}

We investigated the depth of the seismogenic layer based in D95, the cut-off depth at which 95\% of the earthquakes occurred, for five actual cases, such as the 2003 Northern Miyagi, the 2004 Chuetsu, the 2008 Iwate-Miyagi, the 2016 Kumamoto, and the 2016 central Tottori earthquakes. D95 is computed from the relocated event catalog, containing only the background seismicity before the mainshocks occurred. Our results show that for all 5 cases, D95 is deeper or close to the main event depth, and envelops the deeper portion of aftershock distribution and main slip area. A simple modelling of the geothermal gradient based on surface heat flow shows that D95 sits at the crustal temperature of $250-450^{\circ} \mathrm{C}$. Therefore, we concluded that D95 is a suitable parameter to show the bottom of seismogenic layer. And the crustal temperature of $250-450^{\circ} \mathrm{C}$ corresponds with seismogenic layer.

We also witnessed that large earthquakes nucleated at the deepest portion of the seismogenic layer and that the large slip region occurred at shallower than the bottom of seismogenic layer. Some deep aftershocks of the 2016 Kumamoto earthquake, occurred at $5 \mathrm{~km}$ deeper than the bottom of seismogenic depth, are similar phenomenon observed in the 1992 M 7.3 Landers earthquake.

\section{Abbreviations}

D95

Cut-off depth at which $95 \%$ of the earthquakes occurred

D250deg, D300deg, D450deg

Depth of the crustal temperature where it reaches $250{ }^{\circ} \mathrm{C}, 300{ }^{\circ} \mathrm{C}$, and $450{ }^{\circ} \mathrm{C}$

NIED

National Research Institute for Earth Science and Disaster Resilience

$\mathrm{Vp} / \mathrm{Vs}$

P-wave to S-wave velocity ratio

Page 12/23 


\section{Declarations}

Ethics approval and consent to participate

Not applicable.

Consent for publication

Not applicable.

Availability of data and materials

(We are planning to prepare the repository on NIED website or present them in the main paper as tables)

Competing interests

The authors declare that they have no competing interests.

Funding

This study received no specific grant from any funding agency.

Contributions

TEY conceived and planned the framework of the study and carried out the relocation, D95, and crustal temperature computations, and drafted the manuscript. MM adopted the result of $\mathrm{Vp} / \mathrm{Vs}$ and $\mathrm{Vp}$ structure to the study and also help wrap up the study. TM provides available crustal heat flow data and compute crustal temperature of new results for 3 earthquake areas of, the northern Miyagi, the Chuetsu, and the Iwate-Miyagi earthquakes. TI provided local geology of 5 study areas and their insight relate to seismic activity. All authors read and approved the final manuscript.

Acknowledgements

Figures presented in this paper were printed using the Generic Mapping Tools (GMT) software by Wessel and Smith (2009).

\section{References}

1. Aoi, S, Kunugi, T., Fujiwara, H. (2008) Trampoline effect in extreme ground motion, Science, 322(5902):727-30, doi: $10.1126 /$ science.1163113.

2. Chapman DS (1986) Thermal gradients in the continental crust, in The Nature of the Lower Continental Crust, edited by J. B. Dawson et al. Spec Publ Geol Soc London 24:1986

3. Cristensen NI (1996) Poisson's ratio and crustal seismology, J Geophys Res 101:3139-3156. https://doi.org/10.1029/95JB03446

4. Das S, Scholz CH (1983) Why large earthquakes do not nucleate at shallow depths. bNature 305:621-623. https://doi.org/10.1038/305621a0

5. Fowler CMR (2005) The solid Earth, 2nd ed. Cambridge University Press, 685 pp.

6. Fukuyama, E., S. Ishida, D. S. Dreger and H. Kawai (1998) Automated seismic moment tensor determination by using on-line broadband seismic waveforms, Zisin (J. Seismol. Soc. Jpn) Ser. 2, 51, 149-156 (in Japanese with 
English abstract).

7. Hasegawa A., Yamamoto A., Umino N., Miura S., Horiuchi S., Zhao D., Sato H. (2000) Seismic activity and deformation process of the overriding plate in the northeastern Japan subduction zone. Tectonophysics 319:225-239. https://doi.org/https://doi.org/10.1016/S0040-1951(99)00296-6

8. Hashimoto C, Matsu'ura M (2000) 3-D Physical Modelling of Stress Accumulation Processes at Transcurrent Plate Boundaries. pure Appl Geophys 157:2125-2147. https://doi.org/10.1007/PL00001078

9. Honda. R., Aoi, S., Morikawa, N., Sekiguchi, H., Kunugi, T., and Fujiwara, H. (2005) Ground motion and rupture process of the 2004 Mid Niigata Prefecture earthquake obtained from strong motion data of K-NET and KiK-net. Earth Planets Space 57, 527-532.

10. Ishii, T., Y. Yanagisawa, S. Yamaguchi, A. Sangawa, and K. Matsuno (1982) Geology of the Matsushima district, with Geological Sheet Map at 1:50,000, Geological Survey of Japan, 121 pp. (in Japanese with English abstract).

11. Ito K (1990) Regional Variations of the Cutoff Depth of Seismicity in the Crust and Their Relation to Heat Flow and Large Inland-Earthquakes. J Phys Earth 38:223-250. https://doi.org/10.4294/jpe1952.38.223

12. Ito K (1993) Cutoff depth of seismicity and la 379 rge earthquakes near active volcanoes in Japan. Tectonophysics 217:11-21. https://doi.org/https://doi.org/10.1016/0040-1951(93)90198-S

13. Japan Meteorological Agency (2021) The seismological bulletin of Japan. https://www.data.jma.go.jp/svd/eqev/data/bulletin/index_e.html. Accessed 30 Sep 2021

14. Kato, N., Sato, H., Imaizumi, T., Ikeda, Y., Okada, S., Kagohara, K., Kawanaka, T., Kasahara, K. (2004) Seismic reflection profiling across the source fault of the 2003 Northern Miyagi earthquake (Mj 6.4), NE Japan: basin inversion of Miocene back387 arc rift, Earth Planets Space, 56, 1369-1374.

15. Kato, N., Sato, H. and Umino, N. (2006) Fault reactivation and active tectonics on the fore-arc side of the back-arc rift system, NE Japan. J Struct Geol, 28, 2011-2022.

16. Kimura, H., Okamura, Y. (2009) Construction of a fault model based on 3-dimensional structure of fault-related folds in the source area of the 2003 Northern Miyagi earthquake (Mj = 6.4) in NE Japan, Annual Report on Active Fault and Paleoearthquake Researches, 9, 65-78.

17. Kobayashi $Y$ (1976) A relationship between the distribution of focal depth of micro395 earthquakes and surface heat flow in the southwestern Japan and central Japan. Proc. Symp. Earthquake Prediction Research, 184-193, Natl. Comm. Geophys. Seismol. Soc., Jpn., (in Japanese with English abstract)

18. Kubo, H., Suzuki, W., Aoi, S. (2016). Source rupture processes of the 2016 Kumamoto, Japan, earthquakes estimated from strong-motion waveforms. Earth Planets Space 68, 161. https://doi.org/10.1186/s40623-0160536-8.

19. Kubo, H., Suzuki, W., Aoi, S. (2017) Source rupture process of the 2016 central Tottori, Japan, earthquake (M JMA 6.6) inferred from strong motion waveforms. Earth Planets Space 69, 127. https://doi.org/10.1186/s40623-017$0714-3$

20. Lachenbruch AH (1970) Crustal temperature and heat production: Implications of the linear heat-flow relation. J Geophys Res 75:3291-3300. https://doi.org/10.1029/JB075i017p03291

21. Maeda, S., Matsuzawa, T., Yoshida, K., Okada, T., Yoshida, T. (2019) Causes of the N408

22. S compressional aftershocks of the $E-W$ compressional 2008 Iwate-Miyagi Nairiku earthquake (M7.2) in the northeastern Japan arc, Earth, Planets and Space 71:94, https://doi.org/10.1186/s40623-019-1073-z

23. Matsubara, M., H. Sato, T. Ishiyama, a 411 nd A. D. Van Horne (2017) Configuration of the Moho discontinuity beneath the Japanese Islands derived from three-dimensional seismic tomography, Tectonophysics, 710-711, 97107, https://doi.org/10.1016/j.tecto.2016.11.025.

Page $14 / 23$ 
24. Matsubara M, Sato H, Uehira K, Mochizuki M, Kanazawa T, Takahashi N, Suzuki K, Kamiya S (2019) Seismic Velocity Structure in and around the Japanese Island Arc Derived from Seismic Tomography Including NIED MOWLAS Hi-net and S-net Data. Seism Waves - Probing Earth Syst IntechOpen:1-19.

https://doi.org/10.5772/intechopen.86936

25. Matsumoto $T$ (2007) Terrestrial heat flow distribution in Japan area based on the temperature logging in the borehole of NIED Hi-net. In: AGU Fall Meeting Abstracts

26. Matsumoto T, Yamada R, lizuka S (2022) Heat Flow data and Thermal Structure in North East Japan. Earth Planets Space. (submitted)

27. Nakano, S., Nishiki, K., Takarada, S., Hoshizumi, H., Ishizuka, Y., Itoh J., Kawanabe, Y., Oikawa, T., Furukawa, R., Geshi, N., Ishizuka, O., Yamamoto, T., Kishimoto, K. (2013) Volcanoes of Japan (3rd ed.), Geological Survey of Japan, AIST.

28. National Astronomical Observatory (1998) Rika Nenpyo (Chronological Scientific Tables), 1058 pp. (in Japanese)

29. National Institute of Advanced Industrial Science and Technology (2016a) Kumamoto Earthquakes and related information, https://www.gsj.jp/en/hazards/earthquake-hazards/index.html (accessed 13 November 2020).

30. National Institute of Advanced Industrial Science and Technology (2016b) 2016 central Tottori Prefecture earthquake and related information, https://www.gsj.jp/en/hazards/earthquake/tottori2016/index.html (accessed 13

31. November 2020).

32. National Research Institute for Earth Science and Disaster Resilience (2019) NIED Hi433 net, National Research Institute for Earth Science and Disaster Resilience, https://doi.org/10.17598/NIED.0003.

33. Niigata Prefectural Government, Geology of the Niigata Prefecture, with Geological Sheet Map at 1:200,000, Niigata Prefectural Government, 200 pp., 2000 (in Japanese).

34. Nishimura, T., Imakiire, T., Yarai, H., Ozawa, T., Murakami, M., Kaidzu, M. (2003) A preliminary fault model of the 2003 July 26, M6.4 northern Miyagi earthquake, northeastern Japan, estimated from joint inversion of GPS, leveling, and InSAR data, Earth Planets Space, 55, 751-757.

35. Obara K, Kasahara K, Hori S, Okada Y (2005) A densely distributed high-sensitivity seismograph network in Japan: Hi-net by National Research Institute for Earth Science and Disaster Prevention., Rev. Sci. Instrum., 76, 021301-1-021301-12, https://doi.org/10.1063/1.1854197

36. Okada, Y., K. Kasahara, S. Hori, K. Obara, S. Sekiguchi, H. Fujiwara, A. Yamamoto

37. Recent progress of seismic observation networks in Japan - hi-net, F-net, K-net and KiK-net. Earth, Planets Sp., 56 (2004), 10.1186/BF03353076

38. Omuralieva AM, Hasegawa A, Matsuzawa 443 T, Nakajima J, Okada T (2012) Lateral variation of the cutoff depth of shallow earthquakes beneath the Japan Islands and its implications for seismogenesis. Tectonophysics 518-521:93-105, https://doi:.org/10.1016/j.tecto.2011.11.013

39. Research Group for Active Faults of Japan (RGAFJ) (1991) Active faults in Japan. University Tokyo Press, Tokyo

40. Rolandone, F., Burgmann, R., and Nadeau, R. M. (2004) The evolution of the seismic-aseismic transition during the earthquake cycle: Constraints from the time-dependent depth distribution of aftershocks. Geophysical Research Letters, vol.31, L23610, doi:10.1029/2004GL021379

41. Ruina, A (1983) Slip instability and state variable friction laws, J. Geophys. Res., 88, 10359-10370, https://doi.org/10.1029/JB088iB12p10359.

42. Sakagawa Y, Umeda K, Asamori K (2005) Heat flux distribution in Japan with advection taken into account and non-isothermal flow simulation of Unzen volcano. Genshiryoku Bakkuendo Kenkyu, Vol. 11. 2:157-165(in 
Japanese with English abstract)

43. Sakagawa Y, Umeda K, Suzuki M, Kajiwara T, Uchida Y (2004) Database on the Temperature Profiles of Boreholes in Japan. Zisin 57(1):63-67, https://doi.org/10.4294/zisin1948.57.1_63(in Japanese)

44. Sasada M (1985) The pre Neogene basement rocks of the Kamuro Yama Kurikoma Yama area, Northeastern Honshu, Japan Part 2, Boundary between the Abukuma and Kitakami belts. J Geol Soc Japan 91(1):1-17 (in Japanese with English abstract)

45. Sato, H. (1989), Degree of deformation of late Cenozoic strata in the Northeast Honshu Arc, Mem. Geol. Soc. Jpn. 32, 257-268 (in Japanese with English abstract)

46. Sato, H. (1992). Late Cenozoic tectonic evolution of the central part of Northern Honshu, Japan. Bull. Geol. Surv. Japan, vol. 43 (1/2), p. 119-139. (in Japanese with English abstract)

47. Sato, H.(1994): The relationship between late Cenozoic tectonic events and stress field and basin development in northeast Japan. J Geophys Res, 99, 22261-22274.

48. Sato, H., T. Yoshida, T. Iwasaki, T. Sato, Y. Ikeda, and N. Umino (2004a), Late Cenozoic tectonic development of the back arc region of central northern Honshu, Japan, revealed by recent deep seismic profiling, J. Japanese Association for Petroleum Technology, 96, 145-154 (in Japanese with English abstract).

49. Sato, H., N. Kato, T. Imaizumi, Y. Ikeda, S. Okada, K. Kagohara, S. Ogino, T. Kawanaka, and K. Kasahara (2004b) Seismic reflection and refraction profilings across the source fault of the 2003 Northern Miyagi earthquake, Report on the results of the Grant-in-Aid for Scientific Research, No. 15800009, Tohoku Univ., Sendai, 5-20 (in Japanese).

50. Scholz CH (1988) The brittle-plastic transition and the depth of seismic faulting. Geol Rundschau 77:319-328. https://doi.org/10.1007/BF01848693

51. Scholz CH (1998) Earthquakes and friction laws. Nature 391:37-42

52. Shibazaki B (2002) Nucleation of large earthquakes determined by the seismic- aseismic boundary: agreement between models and observations. Phys Earth Planet Inter 134:129-138. https://doi.org/10.1016/S00319201(02)00160-7

53. Sibson RH (1982) Fault zone models, heat flow, and the depth distribution of earthquakes in the continental crust of the United States. Bull. Seism. Soc. Am. 72:151-163.

54. Sibson RH (1984) Roughness at the base of the seismogenic zone: contributing factors. J. Geophys. Res.c1 89:5791-5799. https://doi.org/10.1029/JB089iB07p05791.

55. Stein CA (1995) Heat flow of the Earth. In: "Global Earth Physics, A Handbook of Physical Constants," T. J. Ahre. Am. Geophys. Union, pp 144-158

56. Suzuki, W., Aoi, S., Sekiguchi, H. (2010) Rupture Process of the 2008 Iwate-Miyagi Nairiku, Japan, Earthquake Derived from Near-Source Strong-Motion Records. Bulletin of the Seismological Society of America ; 100 (1): 256-266. doi: https://doi.org/10.1785/0120090043

57. Takemura, M (2005) Re-evaluation of Magnitude and Focal Region of the 1900 Northern Miyagi Prefecture Earthquake in Japan :Comparison with the 1962 and the 2003 Events, Jishin. Vol 58, Num 1, pp 41-53.

58. Tanaka A (2004) Geothermal gradient and heat flow data in and around Japan (II): Crustal thermal structure and its relationship to seismogenic layer. Earth, Planets Sp 56:1195-1199. https://doi.org/10.1186/BF03353340

59. Tanaka A (2009) Lithospheric Thermal Structure : One of Factors Influencing Depth of Earthquakes. Zisin 61:239-245. https://doi.org/10.4294/zisin.61.239(in Japanese with English abstract).

60. Tanaka A, Ishikawa Y (2002) Temperature distribution and focal depth in the crust of the northeastern Japan. Earth, Planets Sp 54:1109-1113. https://doi.org/10.1186/BF03353310 
61. Tanaka A, Ishikawa Y (2005) Crustal thermal regime inferred from magnetic anomaly data and its relationship to seismogenic layer thickness: The Japanese islands case study. Phys Earth Planet Inter 152:257-266. https://doi.org/10.1016/j.pepi.2005.04.011

62. Turcotte DL, Schubert G (1982) Geodynamics applications of coninuum physics to gelogic problems. John Wiley and Sons.

63. Ukawa M, Ishida M, Matsumura 508 S, Kasahara K (1984) Hypocenter determination method of the Kanto-Tokai observational network for microeathquakes. Res Notes Nat Res Cent Disaster Prev. 53:1-88.

64. Umino, N., Okada, T., Nakajima, J., Hori, S., Kono, T., Nakayama, T., Uchida, N., Shimizu, J., Suganomata, J., Gamage, S.S.N., Hasegawa, A., Asano, Y. (2003) Hypocenter and focal mechanism distributions of aftershocks of July 262003 M6.4 northern Miyagi, NE Japan, earthquake revealed by temporary seismic observation, Earth Planets Space, 55, 719-730.

65. Usami, Tatsuo (1987) Shinpen Nihon higai jishin soran (Japanese Edition), University of Tokyo Press. 152-157, 190-191, 195-196

66. Waldhauser F, Ellsworth WL (2000) A Double-difference Earthquake location algorithm: Method and application to the Northern Hayward Fault, California. Bull Seismol Soc Am 90:1353-1368.

https://doi.org/10.1785/0120000006

67. Wessel P, Smith WHF (2009) Generic Mapping Tool (GMT). Options

68. Yano TE, Matsubara M (2017) Effect of newly refined hypocenter locations on the seismic activity recorded during the 2016 Kumamoto Earthquake sequence. Earth, Planets Sp 69:1-10. https://doi.org/10.1186/s40623017-0656-9

69. Yano TE, Takeda T, Matsubara M, Shiomi K (2017) Japan Unified hlgh-resolution relocated catalog for earthquakes (JUICE): Crustal seismicity beneath the Japanese Islands. Tectonophysics 702:19-28. https://doi.org/10.1016/j.tecto.2017.02.017

\section{Figures}



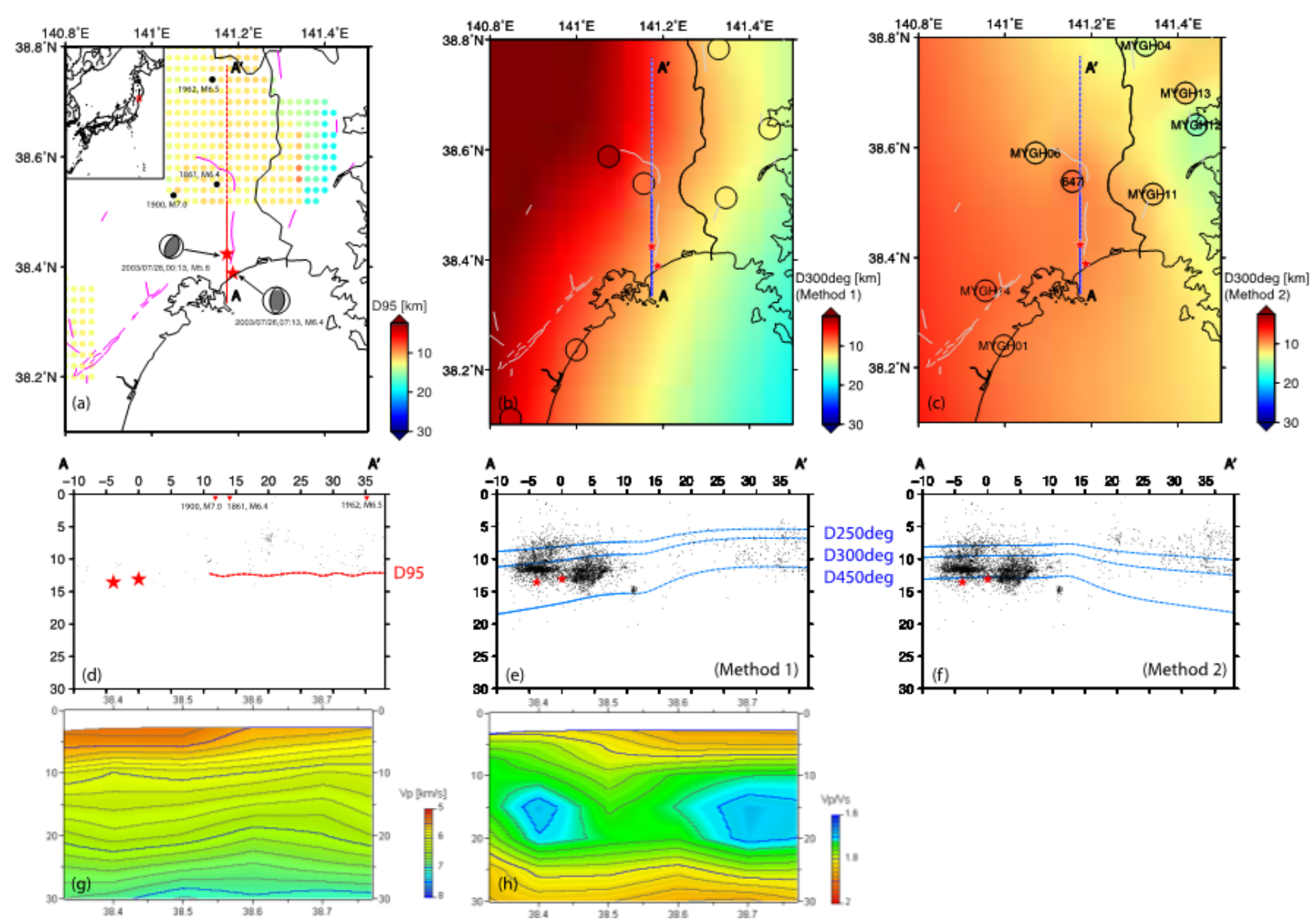

Figure 1

D95 and D250-450deg at the northern Miyagi earthquake site (Case 1)

Spatial distribution in the area of the 2003 northern Miyagi earthquake of (a) D95 and (b) D300deg based on Method 1 and (c) D300deg based on Method 2. Method 1 is the method applied in this paper, and Method 2 is the one introduced in Matsumoto et al. (2022). Each colored circle in (a) indicates the D95 value at each grid. Each circle and its inner color in (b) and (c) indicates the location of the heat flow measurement (Matsumoto, 2007 and Sakagawa et al., 2004, 2005) and estimated D300deg at the location. Colors throughout the map are interpolated using D300deg values at circles. Pink line in (a) and gray line in (b) and (c) are active fault traces listed in RGAFJ (1991). Red stars indicate the mainshock of the 2003 northern Miyagi earthquake, and its major aftershock, and their F-net CMTs (Fukuyama et al., 1998) are shown. The location of the A-A' is based on the trace of Sue fault, F-net CMT, and the aftershock distribution of the 2003 Northern Miyagi earthquake. Three black dots are historical earthquakes by JMA unified catalog (2020) for 1962 event, Usami(1987) for 1861 event, and Takemura(2005) for 1900 events

(d)-(f):Cross-section along the A-A' for D95, background seismicity (occurred before the mainshock (from 2000/10/01 to 2003/07/25)), mainshock, and major aftershock event are indicated in (d) with red broken line, gray dots, and red stars, respectively. Mainshock hypocenter is plotted according to our local relocated depth. Because of lack of seismic data in the southern part of cross section, shown in red solid line in (a), we could only estimate D95 along the red broken line. D250deg, D300deg, and D450deg are shown in (e) and (f) with blue broken lines. The main shock and 
major aftershock event are located at red stars. Aftershocks (occurred from 2003/07/26 to 2012/12/23 within the width between $-10 \mathrm{~km}$ and $10 \mathrm{~km}$ around the cross-section line) of the 2003 Northern Miyagi earthquake.

(g) Vp and (h) Vp/Vs (results from Matsubara et al. (2019) shown in the cross-sections along the line A-A'.
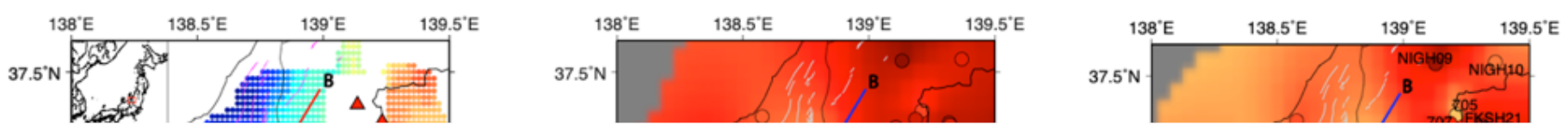

\section{Figure 2}

D95 and D250-450deg at the Chuetsu earthquake site (Case2)

Spatial distribution in the area of the 2004 Chuetsu earthquake of D95 (a) and (b) D300deg based on Method 1 and (c) D300deg based on Method 2. Red triangles in (a) are locations of the volcanoes in the Quaternary Period in Japan (Nakano et al., 2013). Red stars indicate the mainshock of the 2004 Chuetsu earthquake and its F-net CMTs (Fukuyama et al., 1998) are shown. The location of the B-B' is based on the F-net CMT and aftershock distribution of the 2004 Chuetsu earthquake.

(d)-(f): Cross-section along the B-B' for D95 is indicated in (d) with red line. The main shock is located at red star. Gray dots are background seismicity, occurred before the mainshock (from 2000/10/01 to 2004/10/22). Black dots are aftershocks (occurred from 2004/10/23 to 2012/12/27 within the width between $-10 \mathrm{~km}$ and $10 \mathrm{~km}$ around the cross-section line) of the 2004 Chuetsu earthquake shown in (e) and (f).

(g) Vp and (h) Vp/Vs (results from Matsubara et al. (2019) shown in the cross-sections along the line B-B'. Otherwise, colors and marks are the same manner as Figure 1. 

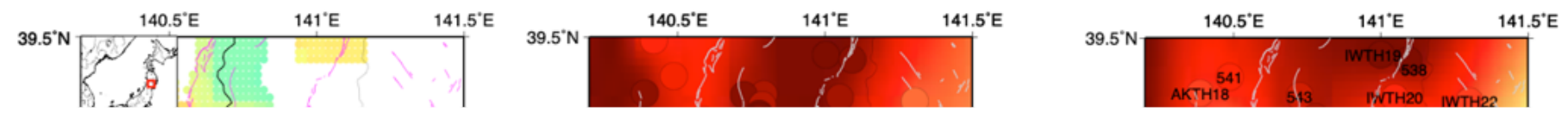

\section{Figure 3}

D95 and D250-450deg at the Iwate-Miyagi earthquake site

Spatial distribution in the area of the 2008 Iwate-Miyagi earthquake of D95 (a) and (b) D300deg based on Method 1 and (c) D300deg based on Method 2. Red triangles in (a) are locations of the volcanoes in the Quaternary Period in Japan (Nakano et al., 2013). Red stars indicate the mainshock of the 2008 Iwate-Miyagi earthquake and its F-net CMTs (Fukuyama et al., 1998) are shown. The location of the C-C' is based on the F-net CMT, and aftershock distribution of the 2008 Iwate-Miyagi earthquake.

(d)-(f): Cross-section along the C-C' for D95 is indicated in (d) with red line. The main shock is located at red stars. Gray dots are background seismicity, occurred before the mainshock (from 2000/10/01 to 2008/06/13). Black dots are aftershocks (occurred from 2008/06/14 to 2012/12/31 within the width between $-10 \mathrm{~km}$ and $10 \mathrm{~km}$ around the cross-section line) of the 2008 Iwate-Miyagi earthquake shown in (e) and (f).

(g) Vp and (h) Vp/Vs (results from Matsubara et al. (2019) shown in the cross-sections along the line C-C'. Otherwise, colors and marks are the same manner as Figure 1. 

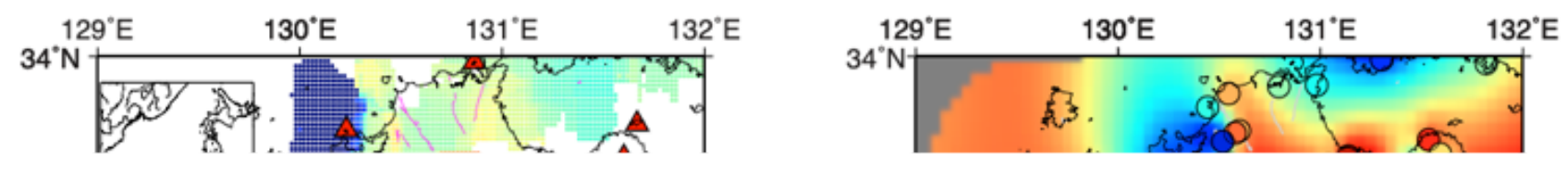

\section{Figure 4}

D95 and D250-450deg at the Kumamoto earthquake site

Spatial distribution in the area of the 2016 Kumamoto earthquake of D95 (a) and (b) D300deg. Red triangles in (a) are locations of the volcanoes in the Quaternary Period in Japan (Nakano et al., 2013). Red stars indicate the mainshock of the 2016 Kumamoto earthquake and its F-net CMTs (Fukuyama et al., 1998) are shown. The location of the D-D' is based on the aftershock distribution of the 2016 Kumamoto earthquake and the Futagawa-Hinagu fault zone. Red stars indicate the mainshocks of the 2016 Kumamoto earthquake occurred on 4/14 and 4/16.

(c)-(d): Cross-section along the D-D' for D95 is indicated in (c) with red line. The main shocks are located at red stars. Gray dots in (c) are the background seismicity, occurred before the mainshock (from 2000/10/01 to 2012/12/31), and black dots in (d) are the aftershocks (from 2016/04/14 to 2016/08/31 within the width between -10 km and $10 \mathrm{~km}$ around the cross-section line) of the 2016 Kumamoto earthquake. Locations of the volcanoes close to the crosssection D-D' are indicated in red triangles on top of (c). Mt. Aso is indicated in white filled triangle.

(e) Vp and (f) Vp/Vs (results from Matsubara et al. (2019) along the line D-D' are shown in the cross-sections. Otherwise, colors and marks are the same manner as Figure 1. 

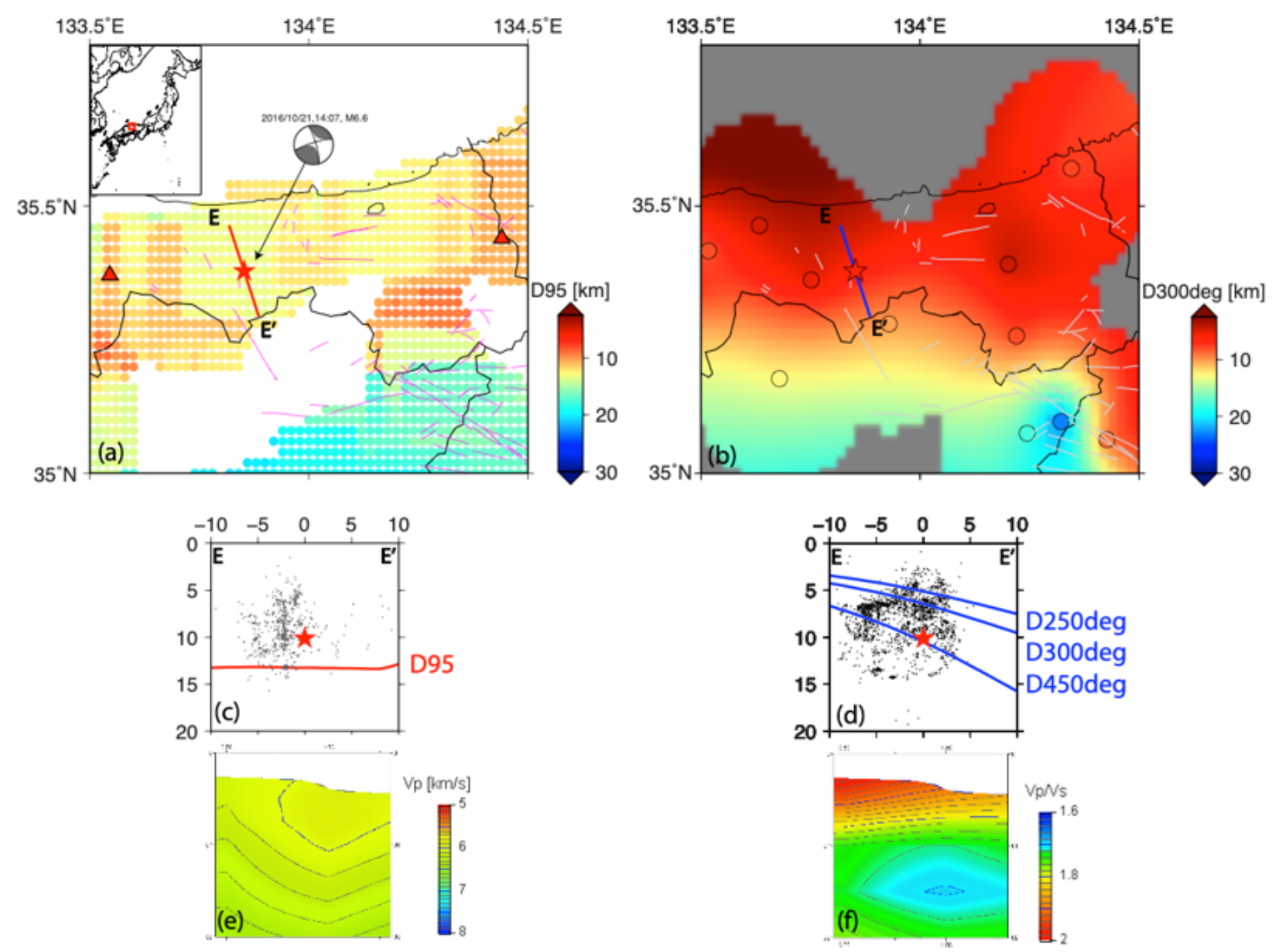

\section{Figure 5}

D95 and D250-450deg at the Tottori earthquake site

Spatial distribution in the area of the 2016 central Tottori earthquake of D95 (a) and (b) D300deg. Red triangles in (a) are locations of the volcanoes in the Quaternary Period in Japan (Nakano et al., 2013). Red star indicates the mainshock of the 2016 central Tottori earthquake and its F-net CMTs (Fukuyama et al., 1998) are shown. The location of the E-E' is based on the F-net CMT, and aftershock distribution of the 2016 central Tottori earthquake.

(c) Cross-section along the E-E' for D95 in red line and background seismicity, occurred before the mainshock (from 2000/10/01 to 2012/12/31) in gray dots. (d) Aftershocks (occurred from 2016/10/21 to 2016/10/24 within the width between $-10 \mathrm{~km}$ and $10 \mathrm{~km}$ around the cross-section line) of the 2016 central Tottori earthquake are shown in black dots. (e) Vp and (f) Vp/Vs (results from Matsubara et al. (2019) along the line E-E' are shown in the cross-sections. Otherwise, colors and marks are the same manner as Figure 1.

\section{Supplementary Files}

This is a list of supplementary files associated with this preprint. Click to download. 
- GraphycalAbstract20220201.png

Page 23/23 